\title{
PERSPECTIVAS SOBRE A MENSTRUAÇÃO: ANÁLISE DAS REPRESENTAÇÕES NA PUBLICIDADE E NA MILITÂNCIA FEMINISTA ONLINE
}

Thaís Melo de Souza ${ }^{1}$

RESUMO: Nesta pesquisa, tenho como objetivo construir uma base teóricometodológica para analisar a representação da menstruação na publicidade veiculada no Brasil, entre 2015 e 2017, bem como o debate fomentado pela produção audiovisual online realizado por militantes feministas nesse mesmo período. Venho neste trabalho explorar referências antropológicas e sociológicas que abordem a representação do corpo feminino em geral e as imposições sociais sobre eles, especialmente através da mídia e que foquem na menstruação e nas suas implicações sociais. Busco compreender a constituição dos estigmas em torno da menstruação e me indago sobre o potencial patologizante que podem exercer. As conclusões desenvolvidas ao longo da pesquisa indicam o quanto os tabus acerca dos corpos femininos ainda exercem grande influência na modelagem de nossos comportamentos: da mulher com o seu próprio corpo e da sociedade em geral com a organicidade do corpo da mulher. Há, de um lado, a militância feminista que problematiza a "patologização" da naturalidade feminina e vem ganhando força cada vez maior, e de outro, a publicidade hegemônica que, em geral, fortalece a rejeição das mulheres de suas "naturalidades", intensificando o desconhecimento de seus próprios corpos.

Palavras-chave: menstruação, feminismo, publicidade, antropologia do corpo.

\section{INTRODUÇÃO}

Este artigo apresenta reflexões acerca das imposições que se dirigem socialmente ao corpo feminino e as manifestações político-comunicacionais que emergem ou se adequam ao âmbito das redes sociais e de compartilhamento de vídeos. Analiso as formas sociais de censura do sangue menstrual e como elas moldam o comportamento feminino e a relação das mulheres com os seus próprios corpos, presentes desde a criação das meninas e potencializadas, também, através da mídia.

\footnotetext{
1 Graduanda do terceiro período no curso Bacharelado Interdisciplinar em Ciências Humanas da Universidade Federal de Juiz de Fora (UFJF). E-mail para contato: thaismelojf@hotmail.com.
} 
Com a análise e apresentação de campanhas publicitárias da mídia brasileira, procuro abordar como a menstruação é representada e como, com a patologização do sangue menstrual, a mídia vende uma ideia de "liberdade" feminina que pode ser adquirida com o consumo dos produtos feitos para lidar com todos os "malefícios" do período menstrual. Busco analisar também como a dominação e o silenciamento dos corpos é realizada e como algumas mulheres - na maioria das vezes, jovens, militantes e feministas - constroem suas ações no sentido oposto dessa estigmatização, lutando pelo fim da censura da "naturalidade" dos corpos femininos e questionando estes padrões de representação dos fluidos corporais de maneira constante e diversificada em termos de criticidade e perspectivas ideológica e teórica adotadas, configurando-se em um meio de visibilidade, informação, debate e também como fonte para pesquisa.

Discutir esse tema em âmbito acadêmico é trazer para o debate e dar visibilidade a um assunto que permanece sendo constrangedor para muitas mulheres de diferentes gerações, que ocupam distintos espaços na sociedade. Procuro evidenciar as formas de censura que moldam o comportamento feminino e afastam as mulheres do conhecimento do próprio corpo. Dessa forma, também busco aqui incentivar o questionamento e a desconstrução desses valores, tendo em vista que a publicidade se apresenta, em geral, como ratificadora de um ideal que não tem a ver com a "natureza" do corpo feminino. O conflito cotidiano da mulher com os fluidos corporais chama atenção para uma dimensão da publicidade que é da falsificação e da desnaturalização da experiência corpórea. Em contrapartida, entra em jogo também na plataforma digital YouTube a voz de militantes feministas que passam a difundir o debate e dão visibilidade ao tema. Elas abordam suas experiências de vida e as formas como lidam com seus corpos e com os julgamentos sociais, possibilitadas através de processos complexos de percepção do corpo, mesmo estando inseridas em uma sociedade considerada machista e que não incentiva a autonomia feminina.

\section{1 - De impureza a patologia}


Uma mulher que tem um fluxo, seu fluxo é sangue de seu corpo. Ela estará sete dias em sua incapacidade cúltica devido à sua menstruação, e quem a tocar, estará impuro(a) até o anoitecer. Tudo sobre o que ela se deitar menstruada está impuro, e tudo sobre o que ela se senta, está impuro. Cada um que tocar seu leito, lave suas vestimentas e banhe-se em água, e ele estará impuro até o anoitecer. Cada pessoa que tocar qualquer objeto sobre o qual ela senta, lave suas vestimentas e banhe-se em água, e estará impura até o anoitecer. (Levítico $15,19-22)$

Algumas passagens da Bíblia, como a reproduzida acima, refletem o quanto a mulher é considerada impura no período menstrual. Através desses escritos, a sociedade ocidental cristã é influenciada pela concepção do corpo da mulher que estigmatiza o sangue menstrual. Essa postura diante da naturalidade corpórea e de como deve ser o comportamento (de rejeição) durante esses dias, tem resquícios fortes até a atualidade, uma vez que o assunto segue sendo um tema vergonhoso e constrangedor para muitas pessoas, de diferentes gerações.

Ao fazer uma análise de como a menstruação é tratada em sociedades diferentes, como os aleutas, os persas e os egípcios, Simone de Beauvoir (1949), afirma que desde a infância é imposto às meninas o silenciamento diante da menstruação. $\mathrm{O}$ assunto é um dos mais difíceis de ser abordado no ambiente familiar, que não ensina para a menina o que vai acontecer com seu corpo e como lidar com o processo menstrual. Ao contrário, é ensinado que a menstruação será o pior período do mês, porque além das dores e alterações constantes de humor, virá o sangue, retratado como algo sujo e vergonhoso (SARDENBERG, 1994), que logo se torna motivo de desconforto e rejeição, como se a partir da primeira menstruação a mulher se tornasse impura (BEAUVOIR, 1949).

Emily Martin (2006) analisa textos de autores do século XIX e livros didáticos de medicina, nos quais a menstruação era relacionada a um processo patológico, tida como um distúrbio, no qual as mulheres ficam fora de controle (MARTIN, 2006), assim como no período da menopausa.

Devido ao constrangimento e à falta de informação decorrentes do incômodo existente ao abordar o assunto, a menstruação "passou a ser vivida solitariamente por cada jovem" (CAMPAGNA \& SOUZA, 2006, p. 11). Muitas meninas não contam nem para suas mães quando menstruam pela primeira vez por causa de vergonha e, como não são 
comuns as conversas sobre o assunto, estas ficam sem respostas para diversas dúvidas e aprendem a lidar sozinhas com algo que, até então, era desconhecido, ou procuram em outras fontes, que não a família, para sanarem a falta de informação, "um processo vivido isoladamente, não compartilhado com a família, nem com amigos" (CAMPAGNA \& SOUZA, 2006, p.26). Portanto, a ausência de discussão sobre a menstruação a invisibiliza, prejudica a relação das mulheres com o próprio corpo em nossa sociedade e fortalece a marginalização existente acerca do tema (RATTI; AZZELLINI; BARRENSE \& GROHMANN, 2015).

É possível observar que a reprodução ainda é considerada a principal finalidade do corpo feminino: "a mulher esboça o trabalho da gestação" (BEAUVOIR, 1949, p.48), o que faz da menstruação símbolo de fracasso, já que representa que a sua finalidade não foi atingida. Em suas análises sobre menstruação, menopausa e parto, Emily Martin (2006) explicita essa ideia:

a menstruação não apenas traz consigo a conotação de um sistema produtivo
que fracassou na produção, como também transmite a noção de uma produção
desvirtuada, fabricando produtos sem uso, fora das especificações,
invendáveis, desperdícios, sucatas. Por mais repugnante que possa ser, o
sangue menstrual irá sair. Uma produção desvirtuada é também uma imagem
que nos enche de horror e consternação. (MARTIN, 2006, p. 93)

O fato da mulher não ter engravidado aparece nos livros de medicina sempre associados a termos negativos, ligados à perda, falta, desintegração e privação: “considerar a menstruação como uma produção que deu errado também contribui para vê-la de forma negativa" (MARTIN, 2006, p.92).

\section{2 - "Liberdade feminina" como mercadoria}

Os mercados biotecnológicos lucram com a possibilidade de correção para os "defeitos" dos corpos femininos (LE BRETON, 2003), o que faz com que os anticoncepcionais contínuos, que suspendem a menstruação, sejam cada vez mais 
vendidos. Através de campanhas e propagandas, os discursos que patologizam a menstruação são potencializados, como na propaganda da marca de absorvente Intimus, com o seguinte slogan: "Crie suas próprias regras com Intimus Evolution Center Sec" (2014), analisada por Ratti, Azzellini, Barrense \& Grohmann (2015). A propaganda aborda o medo que as mulheres têm do vazamento do sangue menstrual e algumas atitudes decorrentes disso, como a escolha das roupas (como se, no período menstrual, a mulher só pudesse usar roupas escuras, para que não corra o "risco" do sangue ficar visível se vazar do absorvente), a preocupação presente em todos os momentos da roupa estar com marcas do absorvente ou do sangue e o medo de manchar algum assento. Ao expor os "incômodos" advindos da menstruação, a propaganda traz a ideia de liberdade associada ao uso do absorvente da marca ao garantir que o produto "prende o fluxo longe da pele e previne vazamentos"(Intimus, 2014).

Após três anos dessa propaganda, a mesma marca de absorvente lançou o comercial "Siga em Frente" (2017), mostrando conquistas profissionais de algumas mulheres, que realizaram suas atividades sem que a menstruação as "atrapalhasse", trazendo a frase: "Vamos tratar a menstruação como ela é. Algo natural, saudável, não um problema”. Analisando as propagandas, é possível perceber que com o passar dos anos, o discurso foi sendo transformado. De uma abordagem que evidencia os incômodos, propondo o uso do absorvente como uma saída, passa a desmistificar que as mulheres são menos capazes no período menstrual, tratando o sangue com mais naturalidade e evidenciando o poder feminino de lidar com essas situações. A partir dessa análise, me questiono sobre a intenção presente na mudança de foco dos comerciais, se é para a desconstrução e para dar visibilidade ao assunto, sem estigmatizá-lo com a ideia de rejeição e de perda de liberdade, ou se com o fortalecimento cada vez maior da luta feminista, as marcas veem a necessidade de mudar suas propagandas para não ser alvo de críticas e se adequarem ao que o público consumidor vem discutindo e assistindo nas redes sociais. 
O blog "Viva sem menstruar", analisado por Ramalho (2013), aborda o direito que a mulher tem de mandar em sua própria vida e fazer suas escolhas, o que significa poder optar pela supressão da menstruação. Os discursos presentes no blog enfatizam sempre a ideia de "liberdade", "escolha" e "direito", evidenciando as dores da cólica e nos seios, a inconstância de humor no período pré-menstrual, o inchaço do corpo e o aumento da acne, trazendo o fim desses sintomas através do uso contínuo de remédios como direito da mulher:

Você decide, não o seu ciclo menstrual. Isso vale para tudo: viajar, namorar, trabalhar e o que mais o seu estilo de vida decidir. A menstruação odeia solidão. Está sempre em má companhia: dor de cabeça, inchaço, dor mamária, alterações de apetite, mudanças de humor etc. [...] Nenhuma mulher quer viver sofrendo. E nem precisa. Deixamos o mais importante para o final. Viver sem menstruar não é apenas conveniente, confortável ou moderninho. Não menstruar pode ajudar a prevenir e tratar doenças bem complicadas. Algumas muito graves, como anemia, mioma e endometriose. (Viva sem menstruar, acesso em: 04/11/2016)

A campanha que potencializa a tendência de suspender por completo a menstruação é divulgada em páginas nas redes sociais e possui um site próprio que conta com um canal de comunicação via web para esclarecer dúvidas. Trazendo a ideia de que a menstruação é um sofrimento que impede a mulher de exercer diversas atividades, apoiada na idealização de felicidade ao suspender a menstruação, dando a ideia do direito e da liberdade que a mulher possui para isso.

É possível observar diversos outros tabus acerca do sangue menstrual disseminado nos discursos dessas propagandas, como o líquido presente no absorvente representando o sangue menstrual, que é azul, fluído e transparente, não é vermelho, viscoso, grosso, com coágulos e opaco como o da menstruação. Trazendo sempre um cenário que ajuda a corroborar com a ideia de limpeza, com as mulheres que estão sempre com roupas claras, felizes e dispostas. Ao analisar as propagandas é evidente a dicotomia entre "as ideias de pureza/impureza e limpeza/sujeira” (NATASOHN, 2005), o que aumenta o silenciamento sobre a naturalidade do corpo das mulheres, distanciando-as do conhecimento sobre si mesmas, porque faz com que acreditem que o sangue é sujo, tem cheiro ruim e deve ser escondido, e consequentemente rejeitado, porque faz a mulher passar por situações 
constrangedoras, que se não fosse a enorme censura que envolve o assunto, poderiam ser entendidas como normais.

Ao associar a menstruação a dores, doenças, gravidez, sintomas ruins no corpo, como cólica e estresse, a biopólítica ajusta os corpos aos padrões que geram lucros aos mercados biotecnológicos e biomédicos. É importante questionar se há, por trás das propagandas destes produtos, a preocupação com a liberdade e o direito das mulheres decidirem sobre os próprios corpos; se o remédio anticoncepcional é realmente benéfico, pois de um lado, evita cólicas, dores, sintomas da TPM, possíveis doenças, gravidez indesejada e permitem que as mulheres tenham maior controle sobre a data que ocorrerá o período, mas, por outro lado, o uso apresenta efeitos colaterais, principalmente no início, aumenta a probabilidade do desenvolvimento de doenças, como câncer de mama e trombose e pode diminuir a libido da mulher, além de fazer o corpo funcionar de forma diferente porque os hormônios presentes nos anticoncepcionais e ingeridos diariamente, fazem com que os hormônios naturais parem de ser produzidos; se as "regras de higiene" vendidas para as mulheres revelam cuidado com o bem-estar de seus corpos ou apenas um aumento na insegurança para criar a necessidade em consumir produtos que geram lucros através da garantia de esconder as naturalidades de seus corpos de várias maneiras; se realmente é necessário ter tanta preocupação se o sangue vai sujar a roupa e alguém vai ver.

As necessidades das mulheres são construídas através de imposições sociais que operam em seus corpos,

O controle da sociedade sobre os indivíduos não se opera simplesmente pela consciência ou pela ideologia, mas começa no corpo, com o corpo. Foi no biológico, no corporal que, antes de tudo, investiu a sociedade capitalista. $\mathrm{O}$ corpo é uma realidade biopolítica. A medicina é uma estratégia de biopolítica. (FOUCAULT, 2011 [1979], p. 80)

\section{3 - Compartilhar, questionar e desconstruir}

Nesta pesquisa, realizo análises em rede de manifestações políticocomunicacionais que emergem ou se adequam ao âmbito das redes sociais, como o 
YouTube, sendo uma plataforma de compartilhamento de vídeos muito difundida entre os usuários da internet, em que é possível ter maior acesso a construções de narrativas autônomas e com diferentes abordagens sobre um mesmo tema.

$\mathrm{Na}$ barra de pesquisa do YouTube, foram pesquisados os termos "feminista menstruação", "tabu menstruação" e "tabus femininos", resultando em um conjunto de 32 vídeos, nos quais apenas 7 foram selecionados para um estudo mais atento. Foram incluídos apenas os vídeos em português, com a publicação datada de 2015 a maio de 2017, feitos por mulheres que se apresentam como feministas, que tenham como foco a abordagem sobre o tabu acerca do sangue menstrual, do desconhecimento e vergonha presentes antes mesmo da primeira menstruação. Na primeira seleção, muitos vídeos abordavam outros assuntos da corporeidade feminina e dos estigmas que a cercam, ou focavam em informar sobre a menstruação, como acontece o período menstrual e quais são os sintomas da tensão pré-menstrual, sem entrar no assunto da estigmatização propriamente dito e, por isso, não foram selecionados para esta pesquisa.

Os relatos e conversas dessas mulheres - na maioria jovens, militantes e feministas que lutam contra a dominação e o silenciamento dos corpos femininos e pelo fim do tabu acerca da naturalidade dos fluídos corporais - abrem espaço para conversas sobre a menstruação que ainda não são comuns entre muitas pessoas. Ao expor suas experiências e incômodos, tais jovens quebram o silêncio que envolve a temática. Os vídeos constituem-se como uma forma de debate, seus canais como meios de tirar dúvidas, de se informar sobre o assunto de maneiras diferentes e problematizar os tabus enraizados na sociedade. A divulgação no Youtube amplia a visibilidade do assunto, pois o acesso é facilitado e pode conectar em rede várias mulheres que recorrem às buscas online sobre o fenômeno da menstruação as afeta.

Na análise dos vídeos selecionados é possível notar que os assuntos abordados pelas youtubers não são muito diferentes dos mencionados anteriormente neste artigo. Apesar do recorte e da abordagem se diferenciarem um pouco, considerando que algumas youtubers fazem uma contextualização histórica ou contam suas próprias experiências, as 
abordagens principais e os questionamentos são muito semelhantes aos realizados ao longo da minha pesquisa.

O primeiro vídeo analisado foi intitulado como "\#PorQueMulher MENSTRUA AZUL? | Episódio 8", divulgado pelo canal "Nunca te pedi nada", de Maira Medeiros, contando com a sua participação e de mais duas mulheres: Mariana Torquato do canal "Vai uma mãozinha?" e Gabi Oliveira do canal "DePretas". Este vídeo foi divulgado no YouTube em 30 de março de 2017, tendo duração de cinco minutos e doze segundos.

Na primeira cena do vídeo é apresentada uma dramatização de tom irônico: uma das personagens é atingida por uma bola e começa a escorrer um líquido azul de sua narina. Com isso evocam o líquido utilizado na publicidade de forma corriqueira para representar o sangue menstrual. As três personagens trajam roupas características da Idade Média e da Grécia Antiga. Saindo da cena dramática, se posicionam em tomada frontal para desenvolver uma contextualização histórica, explicando como o sangue menstrual era visto na Antiguidade, como as mulheres eram tratadas, como tinham que se portar durante o período menstrual e como a abordagem médica, realizada por homens, era feita.

As youtubers questionam a forma silenciosa e patologizante como o sangue menstrual é tratado pela sociedade:

É um processo absolutamente natural e normal. Então por que um pouquinho de sangue uma vez por mês causa tanto desconforto em homens e mulheres?! Por que não se fala abertamente sobre esse assunto? E, principalmente, o que é esse negócio azul nos comerciais de absorventes?!!! (Maira Medeiros)

Nesta pesquisa, ressalto uma passagem da Bíblia que caracteriza como impuros tanto a menstruação quanto a mulher em seu período menstrual, o que pode ser entendido como uma influência muito forte para um comportamento de rejeição à menstruação na sociedade ocidental cristã. No vídeo também é abordado de forma sucinta como a religião cristã impôs alguns comportamentos a respeito do sangue menstrual e como as mulheres foram excluídas da medicina, sendo desenvolvida apenas por homens, ou seja, a forma como a menstruação era estudada e entendida foi desenvolvida por pessoas que não viviam a menstruação: "O sentimento de culpa imposto pela religião e a exclusão da 
mulher da medicina deixaram suas marcas, a menstruação ainda é tratada como um tabu", diz Maíra Medeiros.

Ao mesmo tempo em que é ressaltado no vídeo que a sociedade pode estar tratando o assunto de forma mais madura, é enfatizado o quanto as mulheres ainda são culpabilizadas e se sentem envergonhadas por estarem menstruadas e como ainda relacionam ser uma mulher eficiente com saber "controlar" sua menstruação, sabendo como não torná-la pública: "Apesar de ser um processo natural, a nossa cultura ainda carrega muita vergonha em relação a esse assunto", diz Mariana Torquato.

Existem comportamentos cotidianos que mostram o quanto essa vergonha está enraizada no comportamento das mulheres desde a primeira vez que menstruam: "Muitas meninas menstruam e se sentem constrangidas em falar com os pais sobre isso [...] E mulheres escondem dos seus parceiros que estão menstruadas [...] E um vazamento em público é visto como o pior que pode acontecer na vida da mulher", apontam Mariana Torquato e Gabi Oliveira.

Alguns questionamentos são feitos sobre a postura da sociedade que faz a mulher se sentir mal por estar menstruada, dessa forma é abordada a "vilanização" da tensão prémenstrual (TPM). É possível observar que muitas pessoas relacionam o comportamento de mulheres como se qualquer sinal de tristeza ou raiva estivesse associado aos sintomas pré-menstruais e, assim, não devessem ser levados tão a sério, por ser algo passageiro:

\footnotetext{
Outro resquício medieval é o costume de vilanizar a "tpm", por trás de cada piadinha há uma tentativa de estereotipar a mulher como fraca, problemática, descontrolada, inferior. Por outro lado, os eufemismos da publicidade pouco contribuem para discussão ao associar a menstruação a passear de bicicleta, andar a cavalo, pular de bungee jumping, sempre usando roupas brancas. E senhores, pelo amor de Deus! O nosso sangue é vermelho! Igual ao seu, querido... (Maira Medeiros)
}

Também é problematizada a postura machista da sociedade, uma vez que a menstruação é um processo biológico do corpo das mulheres e talvez seja esse o motivo que o faz ser tão patologizado e silenciado, cabendo a reflexão de como a menstruação seria vista se fizesse parte do corpo masculino. "Menstruar é um processo biológico que nunca vai mudar [...] Já o machismo é um processo social que precisa mudar e é muito 
mais perigoso que uma simples TPM [...] TPM é só às vezes, machismo é sempre!”, afirmam Gabi Oliveira e Mariana Torquato.

O segundo vídeo analisado tem como título: "MENSTRUAÇÃO? QUE NOJO!”, do canal "Dobruskii", publicado em 27 de novembro de 2015, com duração de oito minutos e doze segundos. O vídeo conta com a participação de uma única youtuber, a dona do canal, que relata como, a partir de experiências pessoais e algumas observações, ela começou a questionar sobre os tabus acerca do sangue menstrual e o porquê dos comportamentos sociais serem de tanta rejeição e até mesmo tratarem o assunto como piada e brincadeira.

É relembrado pela youtuber um dia em que ela precisou de absorvente e teve que pedir um em silêncio para sua sogra, recebendo o absorvente que foi escondido no bolso enquanto a outra mulher passava perto das pessoas que estavam no local. A partir daí, a youtuber conta que notou que a vergonha por estar menstruada sempre fez parte de sua vida:

A sociedade, desde quando uma menina nasce, ela já coloca tão evidentemente na nossa cara de que menstruar é repulsivo, é nojento e é sujo. Gente, enfim, em muitos lugares dizem isso e, principalmente, na Bíblia, eu acredito que vem daí o maior nojo que as pessoas sentem por menstruação. Porque tem certas coisas que eu estava lendo na Bíblia, eu vi antes desse vídeo que são coisas assim, sabe, tão profundas, são coisas tão repulsivas, mostra como se a menstruação fosse uma coisa extremamente nojenta e pecaminosa. (Drobuskii)

São diversos os acontecimentos na vida da mulher, principalmente durante o período menstrual que revelam esse silenciamento sobre a menstruação. Como se lidar com isso de forma natural fosse agressivo e uma atitude que não é adequada para as mulheres. A youtuber conta sobre um outro momento marcante do início de sua adolescência, quando o sangue vazou e transpareceu na calça em que ela vestia, sendo motivo para brincadeira de alguns meninos da escola. Ao aprofundar mais nesses questionamentos, a youtuber nota que não achava errado a atitude dos meninos que debochavam dela, mas se via como culpada e repugnante. Dessa forma, é possível observar que esses comportamentos estão tão enraizados na sociedade que fazem as meninas acreditarem que a natureza de seus corpos é suja e tem algo errado acontecendo com ela enquanto menstrua:

Menstruação não é repulsivo, não é motivo de vergonha, é extremamente normal. [...] nós mulheres devemos nos amar, nos respeitar e gostar do jeito que a gente é, sem ligar pras opiniões de terceiros. Eu espero muito que a sociedade em que a gente vive mude esse pensamento, que é debochar de certos seres humanos de algo que nasceu com eles, de algo que é deles. (Dobruskii) 
O canal "Conexão Feminista" publicou o vídeo "Precisamos falar sobre menstruação", no dia 31 de março de 2017, com duração de trinta e oito minutos e dez segundos. O vídeo consiste em uma conversa online entre as duas mulheres que compõem o canal, Renata e Heloisa. É abordado, inicialmente, sobre coletor menstrual, que além de ser sustentável por não poluir tanto quanto o absorvente, permite que a mulher saiba melhor qual é a quantidade de sangue liberado no seu período menstrual. É questionado no vídeo o cheiro forte que não é intrínseco à menstruação, e sim, é exacerbado devido ao uso do absorvente, o que não acontece quando o coletor menstrual é utilizado, no qual é sentido apenas o cheiro próprio do sangue. Porém, é ressaltado que para as empresas que fabricam e vendem absorventes, a divulgação e consumo do coletor menstrual não é tão favorável, porque o lucro gerado pela venda dos absorventes é muito maior, tendo em vista que são descartáveis, sendo utilizados cerca de doze absorventes por mulher em um ciclo.

No vídeo, é apontada a necessidade de discutir e questionar o discurso religioso e tradicional, que ao mesmo tempo que caracteriza as mulheres como impuras quando estão menstruadas e silenciam esse assunto, vangloriam a gravidez, como se não fosse possibilitada pelo sangue menstrual.

As youtubers apontam neste vídeo como ato político uma atleta que não usou absorvente e durante a maratona o sangue vazou e marcou sua roupa, sendo motivo de susto para os telespectadores, gerando polêmica sobre o assunto nos dias seguintes ao ocorrido. É questionado porque quando atletas urinam ou defecam durante uma maratona as pessoas reagem de forma mais pacífica, sem se assustar e gerar notícia sobre isso:

$[\ldots]$ me lembrou que meu maior medo quando ficava menstruada quando era adolescente, era passar, vazar! [...] E eu lembro que até mais velha, quando eu ia sair de casa [...] eu perguntava meu marido 'Tá aparecendo? Tá aparecendo que eu to com absorvente?' É um desespero, um desespero! (Heloisa)

É notável que para muitas mulheres conhecer o próprio corpo, o seu sangue menstrual e seu ciclo não é algo tão comum e natural, porque ainda é um assunto muito abafado na sociedade, apesar de ser tão importante. Esse comportamento que invisibiliza o período menstrual é muito influenciado pelo machismo e pela ideia de que a mulher 
tem que estar sempre impecável, escondendo toda naturalidade que não é vista como sensual ou agradável aos olhos dos homens, e não só com a menstruação isso acontece, mas também com o uso de maquiagens, cirurgias para padronizar diversas partes do corpo feminino. Nesse vídeo isso também é abordado:

\begin{abstract}
O reconhecimento do seu próprio ciclo, eu acho muito benéfico pro mundo! É isso, de você entender que nada funciona de um determinado jeito 24 horas por dia, que é o que cabe na nossa sociedade, que é o que exigem da gente o tempo inteiro, que a gente esteja sempre nessa nossa melhor versão, que nossa melhor versão?! Então, isso eu acho muito importante, porque quebra um paradigma. Não vou funcionar o tempo inteiro, porque eu não sou uma máquina pra funcionar, eu sou uma pessoa! (Renata)
\end{abstract}

As youtubers também conversam sobre sexo enquanto a mulher está menstruada, que em vários casos reflete a misoginia da sociedade, porque muitas pessoas sentem nojo e acreditam que a mulher não pode ter relações sexuais durante esse período. Existem sociedades (não são apontados nomes no vídeo) que fazem a mulher ficar reclusa durante o período menstrual, baseando-se na impureza da mulher e da menstruação:

Do ponto de vista da nossa sociedade que parabeniza as mulheres porque elas podem ser mães, parabeniza e estimula, e julga quem não quer ser mãe, faz muito sentido a menstruação ser uma vergonha. Porque cada vez que você menstrua, você falha como uma pessoa que não reproduziu. [...] O nosso corpo não funcionou como a sociedade pede. (Renata)

O quarto vídeo analisado "Papo de amigas: menstruação, coletor menstrual e tpm", do canal "Clube do Bordado", foi divulgado no YouTube dia 3 de agosto de 2016, tendo dezesseis minutos e cinco minutos de duração. Quatro youtubers conversam sobre o coletor menstrual e contam suas experiências, como fazem para colocar ou tirar e quais são suas impressões, vendo a mudança de cor do sangue ao longo dos dias, tendo contato com a quantidade de sangue, além de estar relacionado ao conhecimento do próprio corpo, apesar de não ser utilizado por muita gente. “Gente, no final das contas o copinho é igual à liberdade. E autoconhecimento. É você se descobrir de uma forma que você não tinha se descoberto antes".

Também é questionado a sensação ruim que as mulheres sentem sobre o próprio sangue, e como isso foi mudando para elas em decorrência do uso do coletor menstrual, "Eu perdi o nojo. Essa história do cheiro é muito maravilhosa! Até porque quando a 
pessoa usa absorvente, principalmente o externo, fica um fedor do caralho. E aquilo ali fica em contato com o seu corpo, por fora, eu não acho legal”.

As youtubers citam que há uma relação entre o ciclo menstrual e as fases da lua, por exemplo, na lua cheia o fluxo fica mais intenso e mulher sente mais dores. Contam como mudaram a relação com o próprio sangue e com a tensão pré-menstrual também: "A partir daí, eu parei de me importar com a minha TPM. Eu sei que eu vou ficar mais sensível ou mais irritada, mas eu abraço ela. Dar lugar pra ela se manifestar, né?! Vamos abraçar a nossa TPM!”.

Por fim, é abordado sobre descobrir e entender mais sobre o funcionamento do próprio corpo, compreender a naturalidade do sangue e a necessidade de falar sobre isso com as outras pessoas:

Nós esperamos com esse vídeo que nós incentivemos o autoconhecimento [...] Vamos deixar umas coisas claras: mulheres menstruam, o sangue existe... E falar abertamente com as amigas, porque tem coisas que você acha que só está acontecendo com você, mas também está acontecendo com sua amiga. Sororidade também, né, gente!

O quinto vídeo analisado neste artigo é do canal "Victoria Ferreira", divulgado no dia 3 de abril de 2017, com duração de dez minutos e cinquenta segundos e intitulado como "PRECISAMOS FALAR SOBRE MENSTRUAÇÃO \#VEDA3". Neste vídeo, a dona do canal traz como assunto principal as informações mais importantes sobre o uso do coletor menstrual e quais são as experiências com o uso. Apontando que o coletor menstrual é mais econômico ao longo do tempo, decorrente da durabilidade do coletor, e menos poluente, favorável à higiene e saúde da mulher, uma vez que o absorvente retém não só o sangue menstrual, mas todo líquido e fluidos que estão na vagina, além de fazer com que o sangue entre em contato com o ar, produzindo cheiro ruim.

A youtuber faz alguns questionamentos sobre o tabu que está presente até mesmo na hora de falar sobre a palavra "menstruação", como se fosse algo inapropriado que deve ser substituído por algumas palavras que terão menos impacto, como se estar menstruada não fosse natural e comum:

Vim falar sobre menstruação, aliás nesse vídeo, gostaria de compartilhar o meu incômodo com as pessoas que não falam "menstruação". Qual é o problema 
com a palavra menstruação?! As pessoas ficam tipo "Ai, tava naqueles dias...”. Gente, "menstruação" não é uma palavra feia, você fala que vai fazer xixi, então porque você não fala que tá menstruada?! (Victoria Ferreira)

Ao finalizar o vídeo, a youtuber relaciona o uso do coletor menstrual com o empoderamento feminino, que possibilita a descoberta do próprio corpo e a maior compreensão do que realmente é o sangue menstrual, sem todos os tabus e censuras que existem para invisibilizá-lo:

Eu me sinto tão confortável, eu não sinto o peso que a menstruação me trazia antes. E transformou a relação com a própria menstruação. Antes eu tinha um nojo que a maior parte das pessoas tem e aí eu percebi que é só sangue, porque cê tira o coletor menstrual e vê o sangue coletado ali. Você percebe que é simplesmente sangue, ele não tem cheiro ruim, ele não tem uma textura grotesca, ele é simplesmente sangue, como se você tivesse se cortado em qualquer lugar do corpo, entende?! Então... É só sangue. E isso foi muito incrível, assim... Foi muito empoderamento, sabe?! [...] Criei uma outra relação comigo mesma, principalmente nesse período de menstruação. (Victoria Ferreira)

O vídeo "MENSTRUAÇÃO: QUEBRANDO OS TABUS SEM NOJINHO” do canal "DRelacionamentos", foi divulgado dia 2 de maio de 2017, com cinco minutos de duração. Quatro youtubers que compõem o canal conversam sobre menstruação, problematizam os tabus, a vergonha e o nojo acerca desse assunto: “Apesar de parecer algo muito natural, ainda existem muitos tabus sobre o tema [...] E estamos em pleno 2017 e as pessoas têm vergonha de falar sobre menstruação e ao mesmo tempo de dizerem que estão menstruadas".

O uso de outros termos para mascarar o período menstrual também é enfatizado no vídeo: "Pensa quantas mulheres você já ouviu falar: 'Não... É porque eu to menstruada'. A maioria fala: 'Não... É porque eu tô naqueles dias'”.

Como foi analisado ao longo da pesquisa, também é abordado nesse vídeo a representação da menstruação nas propagandas de marcas de absorventes, que ilustram o sangue como um líquido azul, "Menstruar é tão feio, tão feio, que até nos comerciais de absorvente (que é um negócio feito pra isso) o liquidozinho é azul. [...] Já viu alguém menstruar azul?!”.

Ao expor os comportamentos que demonstram o quanto as pessoas têm nojo da menstruação, as meninas tentam desconstruir esse tabu: "Não precisa ser motivo de vergonha. Não é pra ser motivo de vergonha. É algo natural do nosso corpo e a gente tem 
que lidar com isso e se desprender um pouco [...] Eu acho que o melhor jeito da gente quebrar isso aí é a gente conhecer nosso próprio corpo".

O último vídeo analisado nessa pesquisa foi divulgado no 26 de agosto de 2016, pelo canal "Neggata" e intitulado como "TABUS FEMININOS", tendo sete minutos e cinquenta e um segundos, no qual duas youtubers (Moniquue e Gleici) questionam os tabus impostos às mulheres acerca da menstruação e da depilação.

Tratam a menstruação com naturalidade, desmistificando a ideia de que é um sangue sujo ou com cheiro ruim, e o fato dele ser eliminado do corpo a cada mês em que a mulher não engravida é um processo biológico natural:

As pessoas associam muito menstruação com uma coisa horrível, ruim. Porque
desde pequena a gente escuta que é a pior época da vida, a época do mês que
cê mais vai sofrer [...] E na real é tudo uma construção social, né... O que é a
menstruação?! A menstruação não é a sujeira do seu corpo saindo. É a camada
mais limpa e mais rica que seu corpo nutriu pra servir o embrião. Ai o que
aconteceu?! O embrião não chegou, ai ela sai... Então, não tem nada, não é
sujo. Não é sujeira. [...] A menstruação em si não tem cheiro, o que deixa
cheiro são os absorventes. [...] (Gleici)

Nesse vídeo também é abordado sobre o coletor menstrual que possibilita que a mulher conheça mais o seu fluxo e a quantidade de sangue que sai na menstruação, fazendo com que vários tabus naturalizados na sociedade sejam questionados:

\begin{abstract}
Eu senti uma grande mudança, de quebra de tabu com o coletor menstrual. Por quê?! Porque com o absorvente eu achava que eu menstruava horrores, porque quando vem assim o fluxo ele desce, espalha, vaza e no coletor não, tu vê que tu menstrua isso aqui sabe?! Dois dedinhos por dia [...] Quando tu bota o OB lá dentro, ele acaba absorvendo as bactérias que te protegem, porque a gente tem bactéria e fungo que protege a gente dentro da nossa vagina. Então, tu bota o absorvente lá e ele absorve tudo, absorve o muco, absorve suas células, absorve umas coisas que não são necessariamente legais de tirar de lá, entendeu?! E aí o coletor vem com essa proposta, tu pensa "Caralho... Eu não sou fedida, era aquele produto que me deixava com um cheiro estranho", "Puts, eu não menstruo tanto assim...", aí tu tem uma ressignificação do que é a menstruação na sua vida. (Gleici)
\end{abstract}

A partir das análises dos vídeos, é possível notar alguns questionamentos e tabus que são citados em quase todos eles, como o desconhecimento do próprio corpo, porque a mulher cresce aprendendo que não pode se tocar, tem que estar comportada, de pernas fechadas, sempre tomando cuidado para esconder sua vagina. Isso gera a falta de autonomia feminina para se descobrir, falar abertamente sobre o assunto, tirar as dúvidas quando começam os primeiros ciclos menstruais e entender as mudanças no corpo. As 
youtubers desmistificam a crença no odor fétido da menstruação, explicando que o cheiro ruim decorre do uso do absorvente. O modo como as mulheres lidam com o corpo e entendem o ciclo menstrual é construída por diversos fatores sociais. O que é muito apontado nos vídeos, principalmente na publicidade, onde a falta de representação da realidade que as mulheres vivem, principalmente pelo sangue que é o líquido azul, mas também pelo padrão das mulheres que participam da propaganda, que não representa grande parte da população e impõe um ideal de beleza e liberdade, impõe essa ideia de rejeição do sangue menstrual. A partir das abordagens feitas nos vídeos, as youtubers trazem uma resignificação da forma como a menstruação é tratada e problematizam os diversos tabus.

\section{4 - Considerações finais: "Nosso sangue não é azul!"}

É possível notar que os discursos da mídia hegemônica sobre a menstruação como algo ruim e que deve ser rejeitado são reproduzidos por muitas meninas. Não questiono nesta pesquisa a veracidade do incômodo e das dores consequentes do período prémenstrual e da descamação do útero e liberação do sangue, mas faço uma reflexão sobre como esses incômodos são tratados diferentemente de outros. De acordo com as análises feitas, é notável a forma que é tratada a menstruação, como rejeição, necessidade de suprimi-la, sendo muito comum a invisibilização do sangue menstrual que faz parte da naturalidade corpórea de grande parte das mulheres. É possível ver essa vergonha ao comparar a maneira como se lida com o sangue menstrual e o sangue de outras partes do corpo, por exemplo, quando uma pessoa se machuca e sangra, esse sangue é tratado de outra forma, não há necessidade de rejeitá-lo, escondê-lo e lidar com ele da maneira mais silenciosa possível. Existem outras dores que as pessoas sentem recorrentemente que advém da natureza do corpo humano, como a eliminação de fezes, que também pode causar dores e, em casos específicos, trazer incômodos. 
Ao analisar a rejeição e o silenciamento da menstruação, busco refletir até que ponto essas reações não são construídas como frutos de uma sociedade misógina que censura o corpo feminino em todas as instâncias que não servem para o prazer sexual dos homens, e como a menstruação seria tratada se fizesse parte da fisiologia dos corpos masculinos também:

Para que possam ver a raiva como uma bênção, e não como doença, talvez seja necessário que as mulheres sintam que sua raiva é legítima. Para que possam sentir que sua raiva é legítima, talvez seja necessário que compreendam sua posição estrutural na sociedade e isso, por sua vez, talvez envolva uma consciência de si mesmas como membros de um grupo ao qual é negada a plena participação na sociedade simplesmente com base no gênero sexual. (MARTIN, 2006, p. 215)

Dessa forma, é importante ressaltar como a "contracorrente" vem ganhando força, através das exposições de arte com sangue menstrual, a venda dos copinhos coletores, as pesquisas, os vídeos e debates realizados por mulheres que falam abertamente sobre o assunto e fazem uma oposição constante: de um lado, os absorventes que são associados ao mercado, opressão, falta de autonomia, falta de conhecimento e distanciamento da mulher de seu próprio corpo e, de outro lado, o coletor menstrual que é associado a melhor qualidade de vida, maior contato com o corpo, crítica ao mercado e ao lucro, tendo um papel emancipatório na perspectiva das mulheres que relatam sobre o uso.

Contudo, a estigmatização acerca da menstruação ainda existe e continua sendo potencializada pela mídia. É possível observar que esse assunto permanece sendo um tema constrangedor e vergonhoso, o desconhecimento do próprio corpo e a rejeição de sua naturalidade permanecem vigentes no discurso e no comportamento de muitas mulheres, de diferentes gerações.

\section{REFERÊNCIAS}

BEAUVOIR, Simone De. O Segundo Sexo. V.1. Rio de Janeiro: Editora Nova Fronteira, 2000.

CAMPAGNA, Viviane Namur; SOUZA, Audrey Setton Lopes de. Corpo e imagem corporal no início da adolescência feminina. Boletim de Psicologia, 2006, 56; 09-35. 
CLUBE DO BORDADO. Papo de amigas: Menstruação, coletor menstrual e tpm. YouTube. 3 ago 2016.2 Disponível em: $<$ https://www.youtube.com/watch?v=3HfiGlc0WUA\& $>$. Acesso em: 25 de abril de 2017.

CONEXÃO FEMINISTA. Precisamos falar sobre menstruação. YouTube. 31 mar 2017.

Disponível em: <https://www.youtube.com/watch?v=oAk_i23Mo4Q\&>. Acesso em: 24 de abril de 2017.

DOBRUSKII. Menstruação? Que nojo! YouTube. 27 nov 2017. Disponível em: $<$ https://www.youtube.com/watch?v=Am363FcVHrU>. Acesso em: 22 de abril de 2017. DRELACIONAMENTOS. Menstruação: quebrando tabus sem nojinho. YouTube. 2 mai 2017. Disponível em: <https://www.youtube.com/watch?v=io2rlbNuGF0\&>. Acesso em: 30 de abril de 2017.

FOUCAULT, Michel. O nascimento da medicina social. In: Microfísica do poder. Rio de Janeiro: Graal, p.79-98, 1979.

LE BRETON, David. Adeus ao corpo: antropologia e sociedade. Trad. Marina Appenzeller. $5^{\text {a }}$ ed. Campinas: Papirus, 2003.

MANICA, Daniela. A desnaturalização da menstruação: hormônios contraceptivos e tecnociência. Horizontes antropológicos, vol.17 n.35. Porto Alegre, Jan./Jun 2011.

MARTIN, Emily. A mulher no corpo: uma análise cultural da reprodução. Rio de Janeiro, Editora Garamond, 2006, 378p.

NATANSOHN, L. Graciela. O corpo feminino como objeto médico e "médiatico". Revista Estudos Feministas, Florianópolis, 13(2): 256, maio-agosto/2005.

NEGGATA. Tabus femininos. YouTube. 29 ago 2016. Disponível em: $<$ https://www.youtube.com/watch?v=88c3soOUCJ8\&>. Acesso em: 30 de abril de 2017. NUNCA TE PEDI NADA. \#PorQueMulher Menstrua Azul? | Episódio 8. YouTube. 30 mar. 2017. Disponível em: <https://www.youtube.com/watch?v=vtIgI482DtY>. Acesso em: 22 de abril de 2017.

RATTI, Claudia Ramos; AZZELLINI, Érica Camillo; BARRENSE, Heloísa; GROHMANN, Rafael. O Tabu da Menstruação Reforçado pelas Propagandas de 
Absorvente. Intercom - Sociedade Brasileira de Estudos Interdisciplinares da Comunicação XXXVIII Congresso Brasileiro de Ciências da Comunicação - Rio de Janeiro - RJ - 4 a 7/9/2015.

VICTORIA FERREIRA. Precisamos falar sobre menstruação \#VEDA 3. YouTube. 3 abr 2017. Disponível em: <https://www.youtube.com/watch?v=_WpmbvDszLQ\&>. Acesso em: 28 de abril de 2017.

VIVA SEM MENSTRUAR. Disponível em: < https://vivasemmenstruar.com.br/>. Acesso em: 2 de dezembro de 2016. 